OPEN ACCESS

Edited by:

Kai Yang,

Indiana University School of Medicine-Lafayette, United States

Reviewed by:

Snehalata Pawar,

Upstate Medical University,

United States

Namratha Sheshadri,

Rutgers University, United States

*Correspondence:

He Huang

huanghe@zju.edu.cn

Yu Lin

linyu517@zju.edu.cn

Specialty section:

This article was submitted to Cell Growth and Division,

a section of the journal

Frontiers in Cell and Developmental

Biology

Received: 15 July 2021 Accepted: 19 November 2021

Published: 23 December 2021

Citation:

Li X, Li Y, Yu Q, Xu L, Fu S, Wei C, Wang L, Luo Y, Shi J, Qian P, Huang H and Lin $Y$ (2021) mTOR Signaling

Regulates the Development and Therapeutic Efficacy of PMN-MDSCs

in Acute GVHD.

Front. Cell Dev. Biol. 9:741911. doi: 10.3389/fcell.2021.741911

\section{mTOR Signaling Regulates the Development and Therapeutic Efficacy of PMN-MDSCs in Acute GVHD}

\author{
Xiaoqing $\mathrm{Li}^{1,2,3,4}$, Yixue $\mathrm{Li}^{1,2,3,4}$, Qinru $\mathrm{Yu}^{1,2,3,4}$, Lin $\mathrm{X} \mathrm{u}^{1,2,3,4}$, Shan $\mathrm{Fu}^{1,2,3,4}$, Cong Wei ${ }^{1,2,3,4}$, \\ Limengmeng Wang ${ }^{1,2,3,4}$, Yi Luo ${ }^{1,2,3,4}$, Jimin Shi ${ }^{1,2,3,4}$, Pengxu Qian ${ }^{2,3,4}$, He Huang ${ }^{1,2,3,4 *}$ and \\ Yu $\operatorname{Lin}^{1,2,3,4 x}$
}

\begin{abstract}
${ }^{1}$ Bone Marrow Transplantation Center, The First Affiliated Hospital, School of Medicine, Zhejiang University, Hangzhou, China, ${ }^{2}$ Liangzhu Laboratory, Zhejiang University Medical Center, Hangzhou, China, ${ }^{3}$ Zhejiang Province Engineering Laboratory for Stem Cell and Immunity Therapy, Hangzhou, China, ${ }^{4}$ Institute of Hematology, Zhejiang University, Hangzhou, China
\end{abstract}

Myeloid-derived suppressor cells (MDSCs) represent a population of heterogeneous myeloid cells, which are characterized by their remarkable ability to suppress $T$ cells and natural killer cells. MDSCs have been proven to play a positive role in protecting acute graft-versus-host disease (aGVHD). Here, we aimed to describe the mechanism behind how mTOR signaling regulates MDSCs' generation and explore its prophylactic and therapeutic potential in aGVHD. Reducing mTOR expression retains myeloid cells with immature characteristics and promotes polymorphonuclear MDSC (PMN-MDSC) immunosuppressive function through STAT3-C/EBP $\beta$ pathway. Prophylactic transfusion of mTOR $^{K O}$ PMN-MDSCs could alleviate $\mathrm{aGVHD}$ while maintaining the graft-versus-leukemia (GVL) effect, which could downregulate the Th1/Th2 ratio, decrease serum proinflammatory cytokines, and increase the proportion of regulatory T cells (Tregs) in aGVHD models at the early stage after transplantation. Moreover, transfusion therapy could promote the reconstruction and function of donor-derived PMN-MDSCs. Not only the percentage and the absolute number of donor-derived PMN-MDSCs significantly increased but also the immunosuppressive ability was much more robust compared to other groups. Altogether, these findings indicated that mTOR is an intrinsic regulator for PMN-MDSCs' differentiation and immunosuppressive function. Together, $\mathrm{mTOR}^{\mathrm{KO}} \mathrm{PMN}-\mathrm{MDSC}$ transfusion can play a protective role in alleviating cytokine storm at the initial stage and promoting the quantitative and functional recoveries of donor-derived PMN-MDSCs in aGVHD.

Keywords: polymorphonuclear MDSCs, mTOR, acute GVHD, GVL effect, allogeneic HSCT

\section{INTRODUCTION}

Allogeneic hematopoietic stem cell transplantation (allo-HSCT) is a potentially curative therapy for different hematopoietic diseases. The graft-versus-host disease (GVHD) represents one of the major complications and causes of death after allo-HSCT, where $\mathrm{T}$ cells play a central role in the pathogenesis and progression of acute GVHD (aGVHD) (Korngold and Sprent 1987; Vogelsang, Lee, and Bensen-Kennedy 2003). Recently, immune-regulatory cell therapy is gaining widespread 
attention in GVHD control, including mesenchymal stromal cells (MSCs) (Ringden et al., 2006; Le Blanc et al., 2008), regulatory T cells (Tregs) (Hess 2006; Koreth et al., 2011), and myeloidderived suppressor cells (MDSCs) (Messmann et al., 2015; Zhang et al., 2019).

MDSCs represent a population of heterogeneous myeloid cells, precursors of dendritic cells (DCs), macrophages, and granulocytes, which accumulate in various pathophysiological settings, such as cancers, chronic inflammations, and autoimmune diseases (Gabrilovich and Nagaraj 2009). Currently, there is a lack of specific gene signatures or surface markers to identify MDSCs among myeloid cells due to their plasticity in different microenvironments. Therefore, their immunosuppressive ability become the most unique feature of MDSCs. In mice, MDSCs are historically defined as cells expressing both Gr1 and CD11b markers. The CD11 b ${ }^{+}$Ly6G $\mathrm{G}^{-} \mathrm{Ly}_{6 \mathrm{C}^{\text {hi }}}$ subset is identified as monocytic MDSCs (M-MDSCs), while the CD11 b ${ }^{+}$Ly6G $\mathrm{G}^{+} \mathrm{Ly} 6 \mathrm{C}^{\text {lo }}$ subgroup is defined as polymorphonuclear MDSCs (PMN-MDSCs) (Bronte et al., 2016). MDSCs exert their suppressive functions via several mechanisms including the expression of enzymes, such as arginase (Arg), nitric oxide synthase (NOS), and indamine 2,3-dioxygenase (IDO); releasing reactive oxygen species (ROS); and inducing Tregs and secreting cytokines (e.g., IL-6, IL-10, and TGF- $\beta$ ) (Dugast et al., 2008; Gabrilovich and Nagaraj 2009; Garcia et al., 2010; Deng et al., 2018).

It has been observed that a higher proportion of MDSCs in grafts was correlated to a lower incidence of aGVHD (Vendramin et al., 2014; Lv et al., 2015; Fan et al., 2017; Wang et al., 2019). The granulocyte colony-stimulating factor (G-CSF) is clinically used as a mobilizer to increase the number of circulating hematopoietic stem cells. Both PMN-MDSCs and M-MDSCs induced by G-CSF could exert suppressive function to reduce aGVHD (Perobelli et al., 2016; D’Aveni et al., 2015). After alloHSCT, MDSCs recovering at the early stage after transplantation presented immunomodulatory properties to suppress donorderived $\mathrm{T}$ cell proliferation and differentiation and promote Tregs development (Mougiakakos et al., 2013; Rieber et al., 2014; Guan et al., 2015). Besides, co-transfusing MDSCs generated in vitro could alleviate aGVHD, while preserving the graft-versus-leukemia (GVL) effect in murine models (Messmann et al., 2015; Zhang et al., 2019). Hence, a better understanding of how to enhance MDSCs' suppressive ability and what are their regulatory networks in vivo requires to be further investigated.

Suppressive MDSCs can be induced and expanded by various methods (Zhou et al., 2010; Gomez et al., 2014). Culturing bone marrow cells for 4 days with G-CSF and granulocyte-macrophage (GM)-CSF can induce functional MDSCs able to inhibit allogeneic $\mathrm{T}$ cell responses in vitro and in vivo (Highfill et al., 2010). MDSCs induced by progenipoietin-1 (a synthetic G-CSF/ Flt-3 ligand molecule) can promote transplant tolerance by inducing MHC class II-restricted, IL-10-secreting, antigenspecific Tregs (MacDonald et al., 2005). mTOR is an evolutionary conserved serine/threonine kinase that plays key regulatory roles in several biological processes, such as cell survival, proliferation, differentiation, metabolism, and autophagy (Beauchamp and Platanias 2013). The activity of mTOR affects the differentiation and functions of various innate and adaptive immune cells, including effector $\mathrm{T}$ cells, Tregs, and antigen-presenting cells (Delgoffe et al., 2009; Thomson et al., 2009; Rao et al., 2010). Targeting mTOR on the recruitment, expansion, and function of MDSCs has been reported in different disease models. Rapamycin, an mTOR inhibitor, regulated the differentiation and suppressive function of MDSCs in protecting against immunological hepatic injury and aGVHD (Zhang et al., 2014; Lin et al., 2018). Additionally, rapamycin could prolong cardiac or corneal allograft survival by inducing MDSCs after transplantation (Nakamura et al., 2015; Wei et al., 2018). However, the underlying mechanisms of how mTOR signals regulate MDSCs are currently not well defined.

In our present study, we demonstrated that the mTOR signaling regulated the suppressive function of PMN-MDSCs through the STAT3-C/EBP $\beta$ pathway. Prophylactic transfusion of mTOR-deficient PMN-MDSCs could play a protective role in alleviating cytokine storm at the initial stage and promote a quantitative and functional recovery of donorderived PMN-MDSCs in aGVHD models. We also explored the mechanism of how mTOR regulated MDSCs and demonstrated that mTOR-deficient PMN-MDSCs might become an effective approach for aGVHD prevention in allo-HSCT.

\section{MATERIALS AND METHODS}

\section{Mice}

Experiments were performed with age-matched $\mathrm{mTOR}^{\mathrm{fl} / \mathrm{fl}}$ (referred to as wild-type, WT control) mice and LysM-Cre $\mathrm{mTOR}^{\mathrm{fl} / \mathrm{fl}}$ (referred as to $\mathrm{mTOR}$ knockout, mTOR KO) mice. LysM-Cre $\mathrm{mTOR}^{\mathrm{fl} / \mathrm{fl}}$ mice were crossed with LysM-Cre and $\mathrm{mTOR}^{\mathrm{fl} / \mathrm{fl}}$ mice, confirmed by genotyping, which were kindly provided by Prof. H Shen. BALB/c (H-2Kd) and C57BL/6 (H$2 \mathrm{~Kb})$ mice were directly purchased from SLAC Laboratory Supplies (China). The CD45.1 congenic mice (C57BL/6) were a gift from Prof. P Qian. Animal experiments were conducted under specific pathogen-free conditions in the Laboratory Animal Center of Zhejiang University and approved by the Institutional Animal Care and Use Committee of Zhejiang University.

\section{Reagents and Antibodies}

The antibodies used for flow cytometric analyses are listed in Supplementary Table S1. Purified Fc Block (anti-mouse FcR $\gamma \mathrm{II} /$ III monoclonal antibody) and isotype control antibodies were obtained from eBioscience. Rapamycin and STAT3 inhibitor were purchased from TargetMol (China). Carboxyfluorescein diacetate succinimidyl ester (CFSE) was purchased from Invitrogen (United States). L-NG-Monomethylarginine, Acetate Salt (L-NMMA) and N(omega)-hydroxy-nor-Larginine (nor-NOHA) were purchased from MCE (United States). Recombinant murine IL-2 was obtained from PeproTech (United States). 


\section{aGVHD and GVL Models}

The MHC-mismatched aGVHD model was used as previously established (Hill et al., 1997; Lin et al., 2018). Briefly, BALB/c mice received $5 \times 10^{6}$ bone marrow $(\mathrm{BM})$ cells (Mouse CD3 Positive Selection, Biolegend) after lethal irradiation with $8 \mathrm{~Gy}$ (split doses of $2 \times 4.0 \mathrm{~Gy} 4 \mathrm{~h}$ apart) for the $\mathrm{C} 57 \mathrm{BL} / 6 \rightarrow \mathrm{BALB} / \mathrm{c}$ combinations. To induce aGVHD, $\mathrm{CD}^{+} \mathrm{T}$ cells were isolated (Pan T Cell Isolation Kit, Miltenyi Biotec) from donor's spleens and given at a dosage of $5 \times 10^{5}$ i.v. on day 0 . Clinical and histopathological scores were assigned following the criteria described by Hill et al. (1997). In GVL models, recipients received grafts containing $2 \times 10^{4}$ A20 tumor cells. Representative samples of GVHD target organs were excised from recipients on day 21 post-BMT and subjected to pathology scoring as previously described (Lin et al., 2018).

\section{Cellular Flow Cytometry}

First, cells were stained with surface markers for $30 \mathrm{~min}$ at $4^{\circ} \mathrm{C}$ in stain buffer (BD Biosciences) and washed with PBS (2\% FBS). Foxp3 and granzyme $\mathrm{B}$ analyses were performed following the manufacturer's instructions (True-Nuclear Transcription Factor Buffer Set, BioLegend). For intracellular staining, cells were fixed and permeabilized with Cytofix/Permwash buffer (BD Biosciences) for $30 \mathrm{~min}$ at $4^{\circ} \mathrm{C}$. Then, they were incubated with intracellular antibodies for another $30 \mathrm{~min}$. Isotype controls were used for intracellular staining, whereas extracellular markers were gated according to the fluorescence minus one control. For T cell intracellular staining, cells isolated from each group were individually cultured for $6 \mathrm{~h}$ in the presence or absence of PMA $(20 \mathrm{ng} / \mathrm{ml})$ and ionomycin $(1 \mu \mathrm{g} / \mathrm{ml})$, with GolgiStop brefeldin A solution (BD Biosciences) during the last $4 \mathrm{~h}$. The FlowJo v.10 software (BD Biosciences) was used to analyze and calculate the MFI for each sample.

\section{Transduction of shRNA}

The specific STAT3 and control shRNA were synthesized by Shanghai GenePharma Co., Ltd (Ling and Arlinghaus 2005). The control (E20150630A) and specific C/EBP $\beta$ (V3LMM_504726) shRNA were purchased from Dharmacon. Briefly, target cells were transduced with lentiviruses accompanied with polybrene $8 \mu \mathrm{g} / \mathrm{ml}$ and centrifuged at $500 \mathrm{~g}$ for $1 \mathrm{~h}$. After $12 \mathrm{~h}$, the serumfree culture medium was replaced by a fresh complete medium and incubated for $48 \mathrm{~h}$. The transfection efficiency was analyzed by flow cytometry.

\section{Cell Isolation and Culture}

A20 (BALB/c B-cell lymphoma cell line) was bought from ATCC and cultured in RPMI-1640 (Gibco) supplemented with 10\% FBS. To detect immunosuppressive function, PMN-MDSCs and M-MDSCs were sorted by MDSC Isolation Kit (Miltenyi Biotec) or flow cytometry cell sorting (BD FACSAria II). Human $\mathrm{CD}^{+} 5^{+}$cells were positively isolated by human CD15 MicroBeads (Miltenyi Biotec) from the bone marrow of healthy volunteers. All subjects signed informed consent forms. The purity was normally over $95 \%$ as assessed by flow cytometry (CytoFLEX LX, Beckman). The isolated PMN-MDSCs were cultured in RPMI-1640 (Gibco) with $2 \mathrm{mM}$ L-glutamine,
$10 \mathrm{mM}$ HEPES, $1 \mathrm{mM}$ sodium pyruvate, $50 \mathrm{mM} 2$ mercaptoethanol, 1\% penicillin/streptomycin (Sigma), and 10\% fetal bovine serum (Gibco) at $5 \% \mathrm{CO}_{2}$ and $37^{\circ} \mathrm{C}$. Media were supplemented with $20 \mathrm{ng} / \mathrm{mL}$ GM-CSF. PMN-MDSCs cocultured with $\mathrm{T}$ cells activated by anti-CD3/CD28 antibodies (Invitrogen) for 3 days were harvested for further studies.

\section{Quantitative RT-PCR}

RNA was extracted using TRIzol (Invitrogen), and cDNA was synthesized using Takara. A SYBR Premix Ex Taq (Takara) RealTime PCR system was used for quantitative PCR. The primers used are shown in Supplementary Table S2. The expression of target genes was determined using the comparative CT $(\Delta \Delta \mathrm{CT})$ method and presented as the "fold change" relative to control samples.

\section{Functional Assay of PMN-MDSCs}

The in vitro-suppressive function of MDSCs was assessed by determining their ability to inhibit $\mathrm{T}$ cell activation as described previously. Briefly, purified $\mathrm{T}$ cells from the spleen were labeled with CFSE $(2.5 \mathrm{mM})$ and plated at a density of $1 \times 10^{5}$ cells/well in $5 \mu \mathrm{g} / \mathrm{ml}$ anti-CD3 antibody-coated, round-bottom, 96-well plates ( $4^{\circ} \mathrm{C}$, overnight) and in the presence of $2 \mu \mathrm{g} / \mathrm{ml}$ soluble anti-CD28 antibody. Isolated MDSCs were added to the wells at the same size ratio. Cell proliferation was determined 3.5 days later by CFSE expression.

\section{Cytokine Measurements}

Serum samples were obtained from different recipients at the time specified. G-Series Mouse Inflammation Array (Ray Biotech) was used for semi-quantitative measurement of mouse cytokines from serum according to the manufacturer's instructions.

\section{Western Blot Analyses}

Protein was extracted from cells using RIPA buffer (Beyotime Biotechnology) with protease and phosphatase inhibitors (Roche Diagnostics GmbH). Samples were electrophoresed through 10\% polyacrylamide gels and immunoblotted with the relevant antibodies using standard methods. The antibodies for $\beta$-actin (4970), mTOR (2972), STAT3 (9139), p-STAT3 (9145), and $\mathrm{C} / \mathrm{EBP} \beta$ (3087) were purchased from CST.

\section{RNA Sequencing}

Total RNA was isolated using TRIzol (Invitrogen), and sequencing libraries were prepared from 10 to $100 \mathrm{ng}$ total RNA using the TruSeq RNA Sample Preparation Kit v2 (Illumina). RNA sequencing (RNA-seq) and the subsequent analyses were completed by Huada Gene Biological Company (China). The heatmap was constructed using the "heatmap" package in $\mathrm{R}$ 3.4.4. The RNA sequencing data were deposited in the Sequence Read Archive (SRA) database: PRJNA726285.

\section{Statistical Analyses}

Experiments were performed with at least three independent biological replicates, and data are presented as means \pm standard deviations (SD). Statistical analyses were performed by 
A

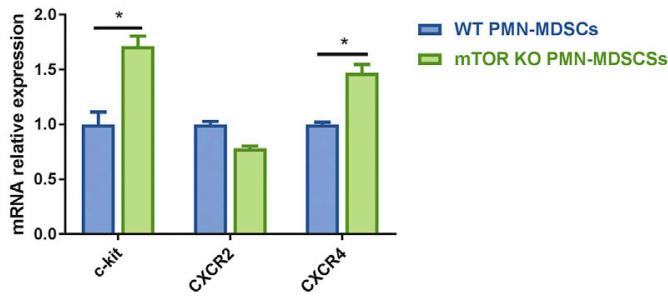

B

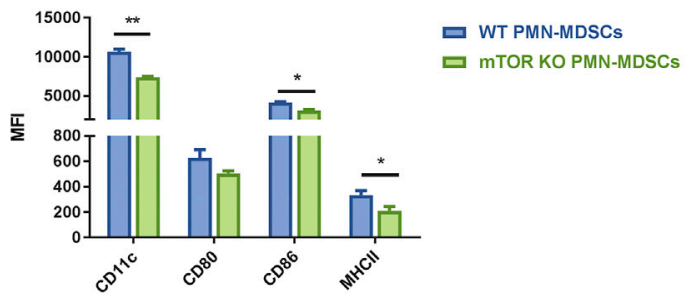

C

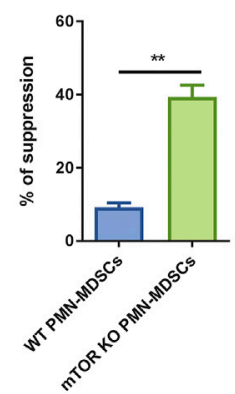

D

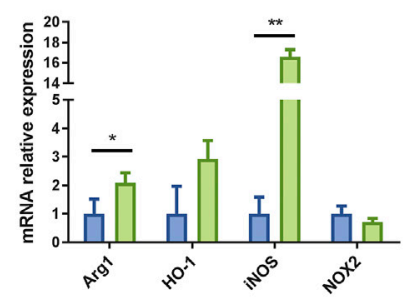

$\mathbf{F}$

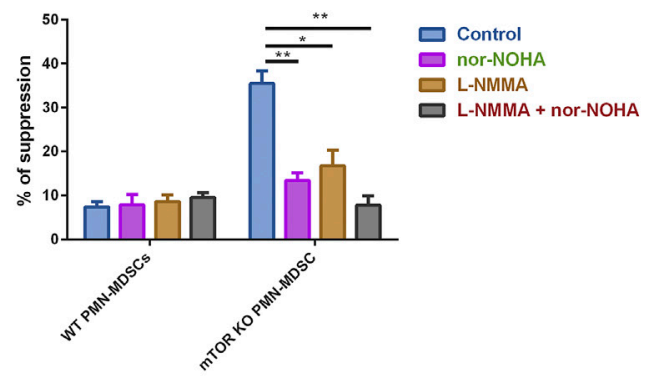

G

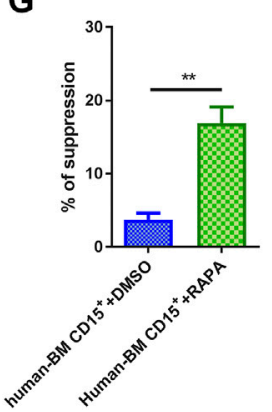

Positive control
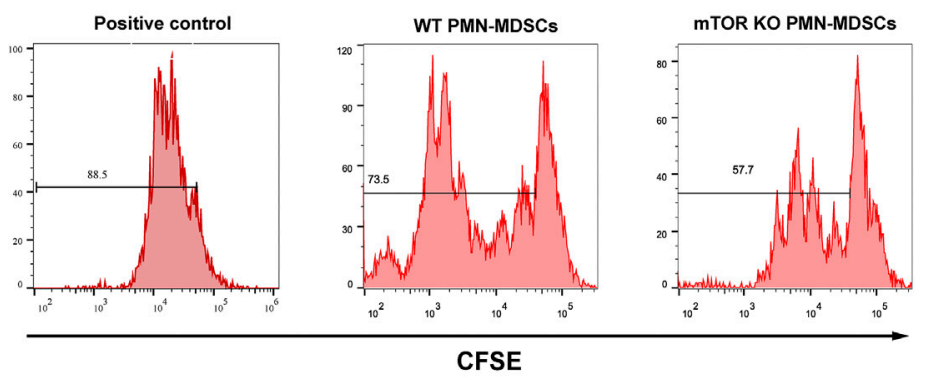

E

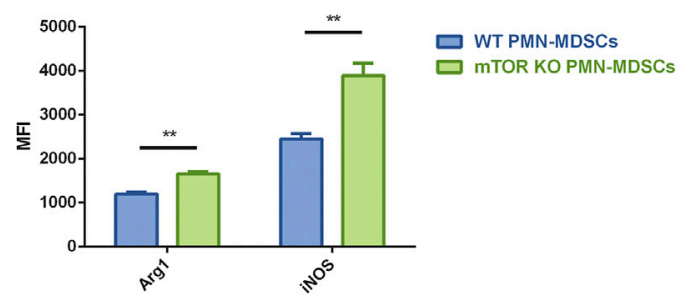

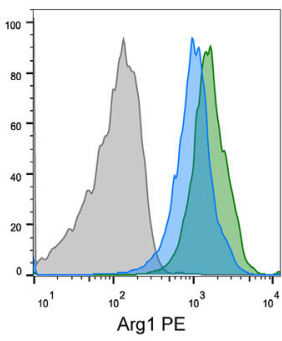

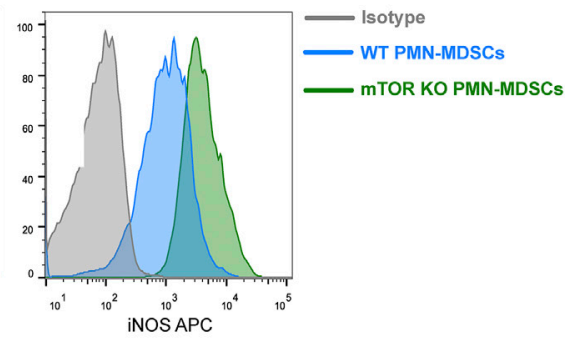

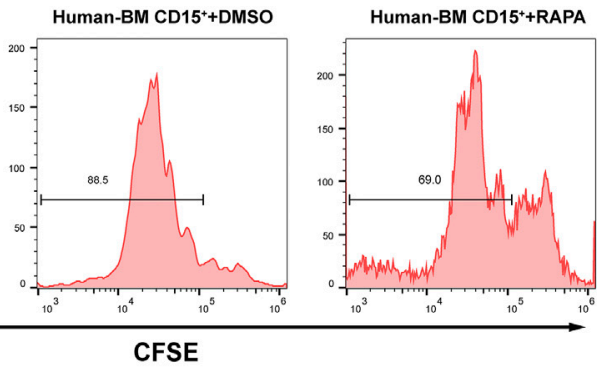

FIGURE 1 | mTOR depletion induced the suppressive function of bone marrow (BM)-derived polymorphonuclear myeloid-derived suppressor cells (PMN-MDSCs). (A) PMN-MDSCs were generated in vitro from $\mathrm{mTOR}^{\mathrm{flfl} l}$ and LysM-Cre $\mathrm{mTOR}^{\mathrm{fl} / \mathrm{fl}}$ mice BM cells co-cultured with active T cells for 3 days. High transcriptional levels of neutrophil precursor markers were detected in TTOR $^{\mathrm{KO}}$ PMN-MDSCs. (B) mTOR depletion downregulated surface maturation markers. (C) Carboxyfluorescein diacetate succinimidyl ester (CFSE)-labeled splenic T cells were stimulated with anti-CD3/CD28 in the presence of wild-type (WT) or mTOR ${ }^{\mathrm{KO}}$ PMN-MDSCs at a 1:1 ratio for 3.5 days. The suppression of splenic T cell proliferation was analyzed and calculated as PMN-MDSCs' suppressive ability (mean \pm SD; $n=8$ ). (D) Transcript 
FIGURE 1 | levels of the MDSC immunosuppressive markers were determined by qPCR (mean \pm SEM; $n=5)$. (E) Flow cytometry analyses of Arg1 and iNOS expression in WT and mTOR ${ }^{\mathrm{KO}}$ PMN-MDSCs after co-culturing with active T cells. Representative Arg1 and iNOS histogram showing overlays of WT PMN-MDSCs, mTOR ${ }^{\mathrm{KO}} \mathrm{PMN}$ MDSCs, and the appropriate isotype control. (F) Arg1 inhibitor (nor-NOHA) and/or iNOS inhibitor [L-NG-Monomethylarginine, Acetate Salt (L-NMMA)] were added in PMN-MDSCs' suppressive function assays. (G) CD15 $\mathrm{BM}$ cells isolated from healthy donors were pretreated with rapamycin for 4 h, which significantly suppressed the active peripheral blood mononuclear cell (PBMC) proliferation compared to DMSO treatment (control). Data are shown as mean \pm SD of one representative experiment of three-four experiments performed. ${ }^{* \star} p<0.01,{ }^{\star} p<0.05 ; p$-values reflected analyses with two-tailed unpaired Student's $t$-test.

conducting an unpaired (two-sided) Student's $t$-test for normally distributed data. The Mann-Whitney $U$ (MWU) test was conducted if the data failed to meet normality criteria. Comparison of the survival curves was generated using the Kaplan-Meier method and compared by log-rank test. To obtain unbiased data, the histopathologic scoring of the aGVHD severity was performed by researchers who were blinded to the treatment groups. A $p<0.05$ was considered statistically significant. All statistical analyses and graphics generation were performed using GraphPad Prism v.7.0 (GraphPad Software, United States).

\section{RESULTS}

\section{Reducing mTOR Expression Retains Myeloid Cells' Immature Characteristics and Promotes PMN-MDSCs' Immunosuppressive Function}

As we previously demonstrated, the mTOR inhibitor rapamycin could induce a strong immunosuppressive function in PMNMDSCs from murine BM in vitro, which prompted us to explore how mTOR regulates MDSCs' generation and function. Thus, we generated mice with myeloid-specific mTOR deficiency by crossing $\mathrm{mTOR}^{\mathrm{fl} / \mathrm{fl}}$ with LysM-Cre recombinase mice. LysMCre $\mathrm{mTOR}^{\mathrm{fl} / \mathrm{fl}}$ (referred to as $\mathrm{mTOR}^{\mathrm{KO}}$ ) mice presented a similar absolute number of BM and spleen (SP) cells with $\mathrm{mTOR}^{\mathrm{fl} / \mathrm{fl}}$ (referred to as WT) control mice (Supplementary Figure S1A). The proportion of PMN-MDSCs and M-MDSCs in the $\mathrm{BM}$ and SP was comparable in $\mathrm{WT}$ and $\mathrm{mTOR}^{\mathrm{KO}}$ mice (Supplementary Figure S1B). mTOR knockout increased the percentage of proliferating cells in $\mathrm{S}$ and $\mathrm{G} 2 / \mathrm{M}$ phases and elevated resistance to apoptosis under active $\mathrm{T}$ cell stimulation (Supplementary Figures S1C, D). The expression of c-Kit and CXCR4 was higher in $\mathrm{mTOR}^{\mathrm{KO}} \mathrm{PMN}-\mathrm{MDSC}$ (Figure 1A), which revealed that they presented precursor myeloid cells characteristics. Additionally, $\mathrm{mTOR}^{\mathrm{KO}}$ PMN-MDSCs had lower expression of MHC II and CD86 compared to WT PMN-MDSCs (Figure 1B), suggesting that loss of mTOR maintains PMN-MDSCs in an immature state.

Next, we determined the effect of mTOR deficiency on the suppressive function of PMN-MDSCs. T cell proliferation assays were performed by co-incubating BM-derived PMN-MDSCs with splenic $\mathrm{T}$ cells. The $\mathrm{mTOR}^{\mathrm{KO}} \mathrm{PMN}-\mathrm{MDSC}$ expressed a stronger immunosuppressive ability compared with WT PMNMDSCs (Figure 1C), while mTOR deficiency ameliorated M-MDSCs' immunosuppressive ability (Supplementary Figure S2A). Due to the larger amount of PMN-MDSCs compared to
M-MDSCs, focusing on PMN-MDSCs as an overall treatment strategy deserves further investigation. Then, we explored the molecular mechanisms underlying their suppressive function. Arg1 and iNOS were significantly upregulated at transcriptional and protein levels in $\mathrm{mTOR}^{\mathrm{KO}} \mathrm{PMN}-\mathrm{MDSCs}$ (Figure 1D, E). The administration of L-NMMA (an iNOS inhibitor) or nor-NOHA (an Arg1 inhibitor), either alone or combined, efficiently reduced immunosuppressive activity (Figure 1F).

Next, we hypothesized whether mTOR played the same role in human myeloid cells. After treating healthy donor BM cells with rapamycin for $4 \mathrm{~h}$, the number of $\mathrm{CD} 15^{+}$cells and PMN-MDSC and M-MDSC proportions were not affected (Supplementary Figure S2B). The rapamycin pretreatment induced human BM $\mathrm{CD} 5^{+}$cells' immunosuppressive function, but the variation degree was much smaller than that of murine cells (Figure 1G). These results showed that mTOR inhibition could promote PMN-MDSCs' suppressive function both in mice and human BM cells.

\section{Reducing mTOR Expression Enhances STAT3 Activity in PMN-MDSCs}

Furthermore, we performed RNA-seq to uncover the molecular mechanisms underlying how mTOR deficiency rejuvenated PMN-MDSCs. A total of 2,860 differentially expressed genes were identified, 631 upregulated and 2,175 downregulated (Supplementary Figure S3A). Particularly, NOS2 showed a pronounced change in $\mathrm{mTOR}^{\mathrm{KO}} \mathrm{PMN}-\mathrm{MDSCs}$, which provided another evidence for the suppressive ability elevation (Supplementary Figure S3B). Through Kyoto Encyclopedia of Genes and Genomes (KEGG) analysis, many immune-related pathways were identified including TNF signaling, PI3K-Akt, and JAK-STAT (Figure 2A). STAT3 and C/EBP $\beta$ were enriched in multiple signaling pathways. Several negative regulators of STAT3 signaling including Pias, SOCS, and PTP cluster were downregulated in $\mathrm{mTOR}^{\mathrm{KO}} \mathrm{PMN}-\mathrm{MDSC}$, but not in WT PMNMDSCs (Figure 2B). The qPCR results validated significant decreases in Pias2 and Pias4 in $\mathrm{mTOR}^{\mathrm{KO}}$ PMN-MDSCs; moreover, the upregulation of STAT3 and C/EBP $\beta$ was also demonstrated (Figure 2C). We verified the role of STAT3 in suppressive function using the STAT3 inhibitor, Stattic. We found that Stattic could significantly reduce the $\mathrm{mTOR}^{\mathrm{KO}}$ PMN-MDSCs' suppressive function (Figure 2D). Meanwhile, the expression of Arg1 and iNOS was downregulated (Figure 2E). Previous studies have shown that $\mathrm{C} / \mathrm{EBP} \beta$ is a downstream target of mTOR and STAT3 signaling pathways (Bitto et al., 2021). Western blot analyses confirmed that C/EBP $\beta$ (at $35 \mathrm{kDa}$ ) increased in $\mathrm{mTOR}^{\mathrm{KO}} \mathrm{PMN}-\mathrm{MDSCs}$ and 


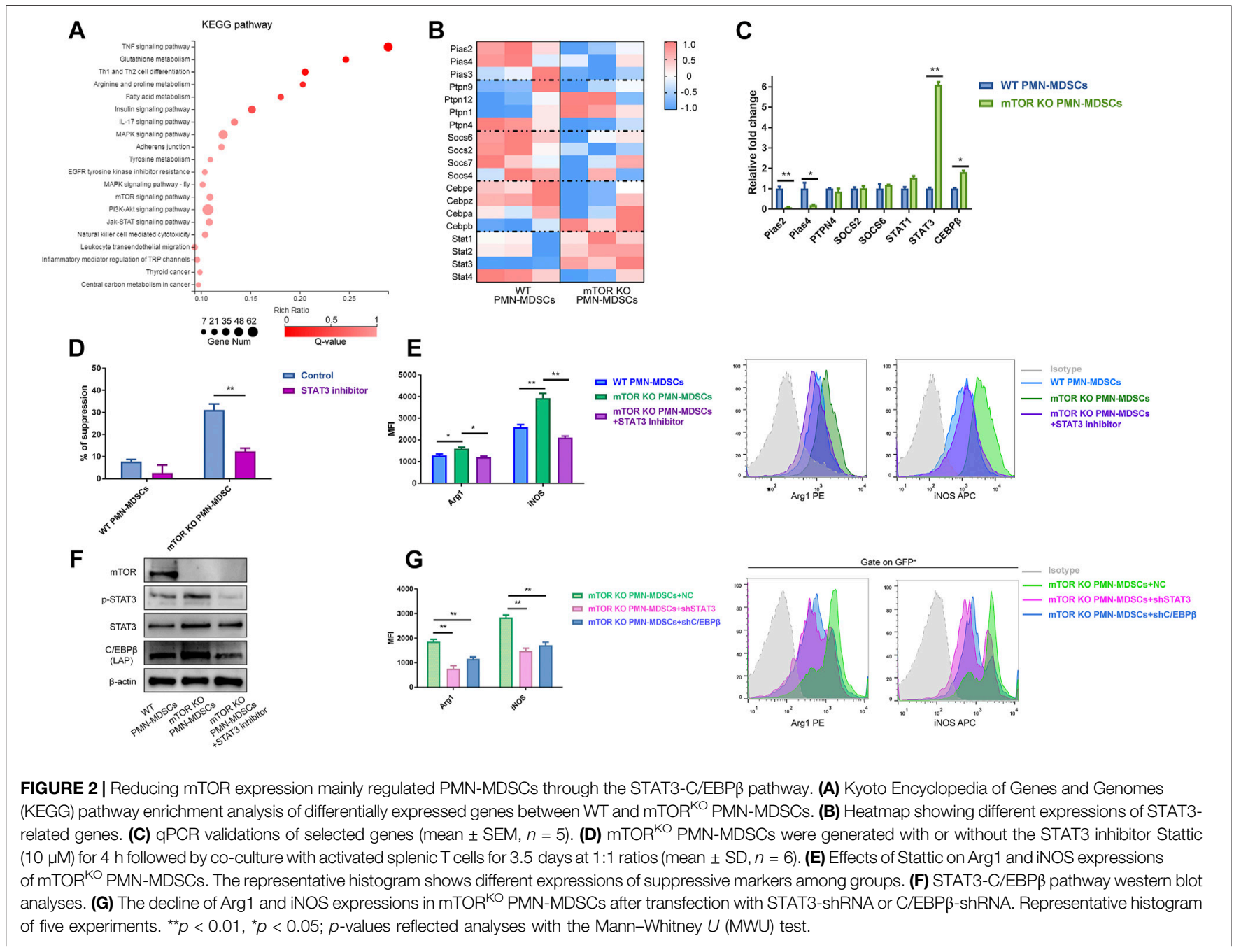

concurrently decreased with the downregulated STAT3 phosphorylation in the group treated with Stattic (Figure 2F). This indicated that STAT3 activation was required for C/EBP $\beta$ expression. To further verify the relationship between STAT3-C/ $\mathrm{EBP} \beta$ signaling and the $\mathrm{mTOR}^{\mathrm{KO}} \mathrm{PMN}-\mathrm{MDSC}$ suppressive function, shRNA was performed to knockdown STAT3 and $\mathrm{C} / \mathrm{EBP} \beta$ in $\mathrm{mTOR}^{\mathrm{KO}} \mathrm{PMN}-\mathrm{MDSCs}$, respectively. STAT3 activation was not affected by C/EBP $\beta$-shRNA (Supplementary Figure S4A, B), but the expression of Arg1 and iNOS decreased in both STAT3-shRNA and C/EBP $\beta$-shRNA groups (Figure 2G). These results indicated that $\mathrm{mTOR}$ regulated the suppressive function of PMN-MDSCs through STAT3-C/ $\mathrm{EBP} \beta$ pathway activation.

\section{mTOR $^{\mathrm{KO}}$ PMN-MDSCs Could Alleviate aGVHD While Retaining the GVL Effect}

Since $\mathrm{mTOR}^{\mathrm{KO}}$ PMN-MDSCs displayed a remarkable immunosuppressive function, we further explored their preventive and therapeutic capacity in murine aGVHD models. First, lethally irradiated BALB/c mice $(\mathrm{H}-2 \mathrm{Kd})$ were reconstituted with $\mathrm{T}$ cell-depleted (TCD)-BM alone or TCD$\mathrm{BM}$ plus $\mathrm{CD}^{+}$splenic T cells from $\mathrm{B} 6$ mice $(\mathrm{H}-2 \mathrm{~Kb})$. Then, WT PMN-MDSCs or $\mathrm{mTOR}^{\mathrm{KO}}$ PMN-MDSCs were transfused with TCD-BM + T cells (Figure 3A). Mice who received TCD-BM alone achieved long-term survival within 60 days. Mice in the $\mathrm{TCD}-\mathrm{BM}+\mathrm{T}$ cells group had poor survival with a mortality rate of around $90 \%$ at 60 days and presented severe clinical aGVHD symptoms, such as weight loss, hunched posture, hair loss, and diarrhea. Histological examination of the intestine, liver, and skin showed severe tissue damage and lymphocyte infiltration. Infusion of WT PMN-MDSCs did not effectively improve the survival or alleviate the aGVHD symptoms. However, in the $\mathrm{mTOR}^{\mathrm{KO}} \mathrm{PMN}-\mathrm{MDSC}$ infusion group, lower mortality rate and aGVHD scores were observed, and nearly $60 \%$ of the mice survived more than 60 days (Figure 3B-D). Lymphocyte infiltration and tissue damage were remarkably relieved, and pathological scores of the liver, intestine, and skin decreased in the $\mathrm{mTOR}^{\mathrm{KO}} \mathrm{PMN}-\mathrm{MDSC}$ infusion group (Figure 3E, F). These observations suggested that $\mathrm{mTOR}^{\mathrm{KO}}$ PMN-MDSC cotransfusion was an effective method to prevent aGVHD after allo-HSCT. However, when the $\mathrm{mTOR}^{\mathrm{KO}} \mathrm{PMN}-\mathrm{MDSC}$ 


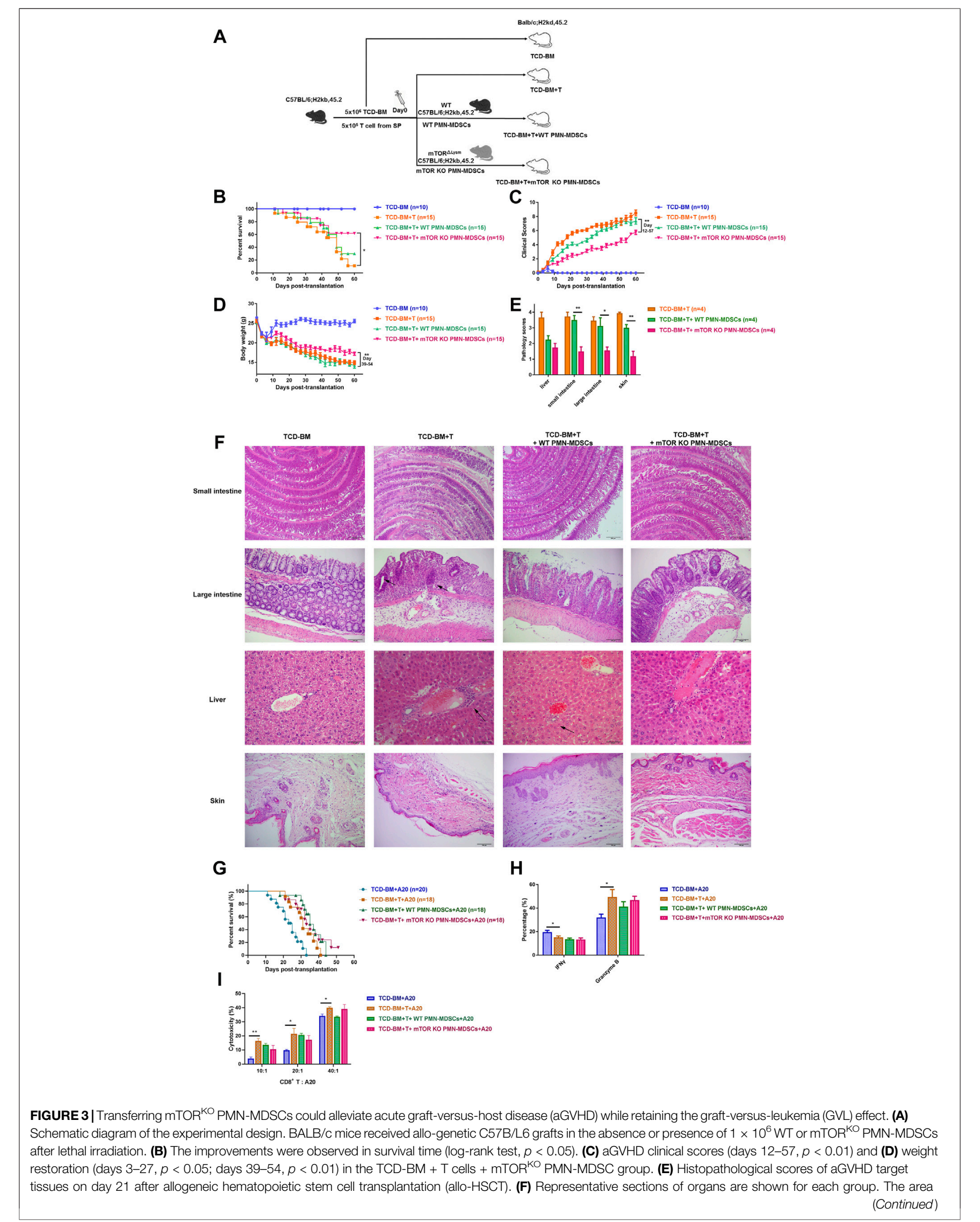


FIGURE 3 | indicated by the arrow shows infiltrated inflammatory cells. (G) The survival of GVL models induced by A2O leukemic cell (H-2d) injection into recipients. (H) The frequency of donor-derived interferon- $\gamma$ (IFN- $\gamma$ ) production and granzyme B expression in CD8 ${ }^{+}$splenic T cells on day 14 . (I) The cytotoxic activity of donor CD8 ${ }^{+}$ T cells was analyzed on day 14 after allo-HSCT. The data above are presented as mean \pm SD and was assessed by unpaired Student's $t$-test (two-sided) or MWU test, pooled from two-three independent experiments, with at least five mice per group. Numerals in brackets indicate the number of mice tested.

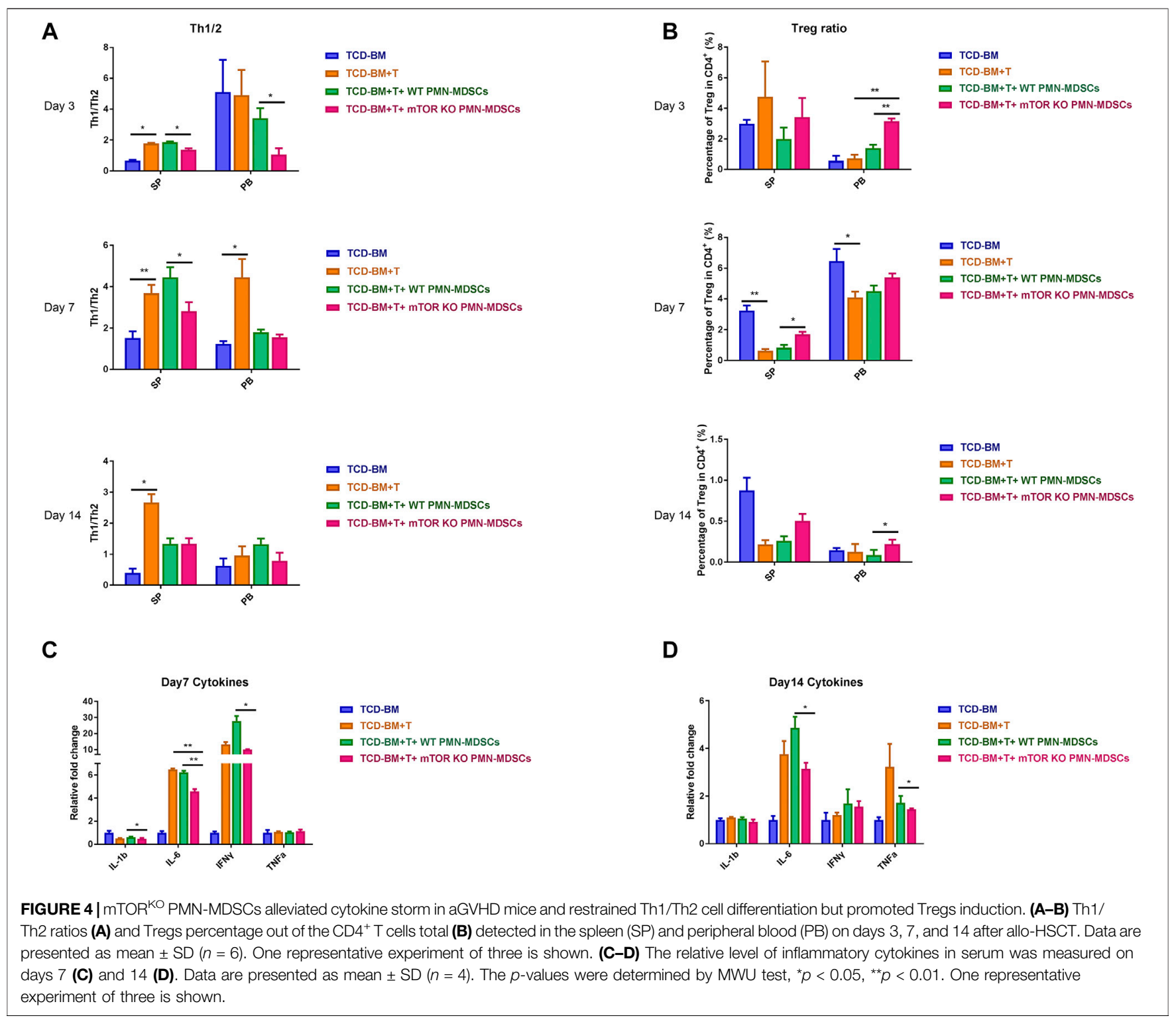

transfusion was performed on day 14 after aGVHD onset, the therapeutic ability was limited (Supplementary Figure S5A). The survival and aGVHD clinical and pathological scores did not differ among the TCD-BM $+\mathrm{T}$ cells, WT PMN-MDSC transfusion, and $\mathrm{mTOR}^{\mathrm{KO}} \mathrm{PMN}-\mathrm{MDSC}$ transfusion groups (Supplementary Figure S5B-F).

Then, A20 cells were injected into recipients to induce tumor development to clarify the influence of $\mathrm{mTOR}^{\mathrm{KO}}$ PMN-MDSCs on the GVL effect. Mice that received only TCD-BM plus A20 cells died within 32 days due to leukemia progression. Mice in the
TCD-BM + T cells plus A20 cells group displayed minimal tumor infiltration but died due to aGVHD-related damage. The $\mathrm{mTOR}^{\mathrm{KO}}$ PMN-MDSC transfusion group showed the best survival compared with other groups (Figure 3G). These results indicated that $\mathrm{mTOR}^{\mathrm{KO}} \mathrm{PMN}-\mathrm{MDSC}$ could actively suppress aGVHD after allo-HSCT while retaining GVL activity. To explore the underlying mechanisms, we examined the activation and functional activity of donor-derived $\mathrm{CD}^{+}$ $\mathrm{T}$ cells, known as the main effector cells governing anti-tumor response. Intercellular staining of effective markers revealed no 


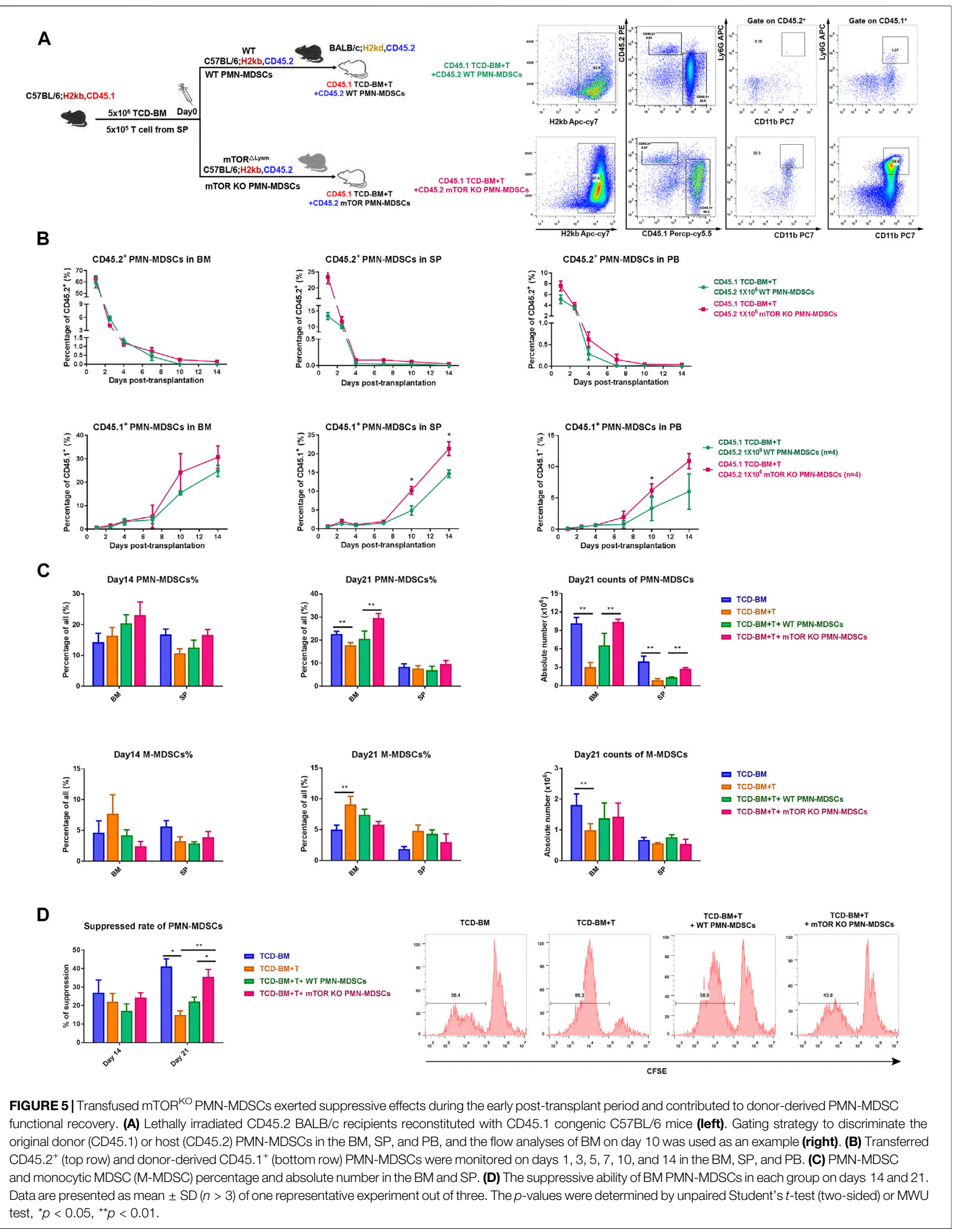


difference in interferon- $\gamma$ (IFN- $\gamma$ ) or granzyme B expression in $\mathrm{CD}^{+} \mathrm{T}$ cells among the $\mathrm{mTOR}^{\mathrm{KO}}$ PMN-MDSC treatment, WT PMN-MDSC treatment, and untreated groups (Figure $3 \mathbf{H}$ ). Correspondingly, isolated $\mathrm{CD}^{+} \mathrm{T}$ cells from $\mathrm{mTOR}^{\mathrm{KO}} \mathrm{PMN}-$ MDSC-treated mice exhibited a cytotoxic activity against allogeneic A20 cells, which showed no clear difference compared with other groups (Figure 3I). These data provided further evidence that the cytotoxic capabilities of donor-derived $\mathrm{CD}^{+} \mathrm{T}$ cells were unaffected by $\mathrm{mTOR}^{\mathrm{KO}} \mathrm{PMN}-\mathrm{MDSCs}$.

\section{mTOR $^{\text {KO }}$ PMN-MDSCs Could Alleviate Cytokine Storm at aGVHD Initial Stage}

Our previous findings confirmed that only co-transfusing mTOR $^{\mathrm{KO}}$ PMN-MDSCs with grafts could exert a protective effect of aGVHD development, rather than a therapeutic activity after aGVHD occurrence. Therefore, we speculated that the infused $\mathrm{mTOR}^{\mathrm{KO}} \mathrm{PMN}-\mathrm{MDSC}$ could restrain donorderived $\mathrm{T}$ lymphocyte activation and expansion at a very early stage of aGVHD. Thus, we analyzed the proportions of several $\mathrm{T}$ cell subsets in each group on days 3, 7, and 14 after transplantation. In peripheral blood (PB) and SP, the T helper cell type 1 versus type 2 (Th1/Th2) ratio was remarkably elevated in TCD-BM $+\mathrm{T}$ cells and WT PMN-MDSC infusion groups, whereas decreased in the $\mathrm{mTOR}^{\mathrm{KO}} \mathrm{PMN}$-MDSCs infusion group (Figure 4A). Since inducing Tregs generation is considered as an important MDSC mechanism to suppress GVHD progression (Edinger et al., 2003; Zhao et al., 2008), we further detected the percentage of Tregs in total $\mathrm{CD} 4^{+} \mathrm{T}$ cells from PB and SP. During the early period after transplantation, mice who received $\mathrm{mTOR}^{\mathrm{KO}}$ PMN-MDSCs had a higher percentage of Tregs compared to other aGVHD groups (Figure 4B). Proinflammatory cytokines in serum including IL-1 $\beta$, IL-6, TNF-a, and IFN- $\gamma$ remarkably increased in the TCD-BM $+\mathrm{T}$ cells and WT PMN-MDSC infusion groups, but reduced in the $\mathrm{mTOR}^{\mathrm{KO}}$ PMN-MDSC infusion group on days 7 and 14 (Figure 4C, D). These findings demonstrated that adoptive transferring of $\mathrm{mTOR}^{\mathrm{KO}} \mathrm{PMN}-\mathrm{MDSC}$ could suppress the activation and proliferation of allo-active $\mathrm{T}$ cells at the beginning of aGVHD, thereby stopping cytokine storm amplification.

\section{mTOR $^{\mathrm{KO}}$ PMN-MDSCs Could Promote a Quantitative and Functional Recovery of Donor-Derived PMN-MDSCs at aGVHD Later Stage}

Next, we investigated how long the infused $\mathrm{mTOR}^{\mathrm{KO}} \mathrm{PMN}-$ MDSC could persist in vivo and whether they could play a longterm suppressive function. Thus, BALB/c mice (H2Kd, CD45.2) received B6-derived TCD-BM + T cells $(\mathrm{H} 2 \mathrm{~Kb}, \mathrm{CD} 45.1)$ with $\mathrm{WT}$ or $\mathrm{mTOR}^{\mathrm{KO}} \mathrm{PMN}-\mathrm{MDSCs}(\mathrm{H} 2 \mathrm{~kb}, \mathrm{CD} 45.2)$ to distinguish the host-derived or co-transfused PMN-MDSCs by CD45.1 and CD45.2 markers (Figure 5A). Both the transfused CD45.2 $2^{+}$ $\mathrm{WT}$ and $\mathrm{mTOR}^{\mathrm{KO}} \mathrm{PMN}-\mathrm{MDSC}$ remained at a relatively high level on day 1 after transplantation, then markedly declined over time. After the transfusion, we found that either WT or $\mathrm{mTOR}^{\mathrm{KO}}$
PMN-MDSCs (CD45.2, H-2Kb) persisted for no more than 10 days in BM, SP, and PB. In contrast, donor-derived PMNMDSCs (CD45.1, H-2Kb) rapidly differentiated from progenitor cells, and the difference between the two groups gradually increased over time (Figure 5B). Therefore, these results indicated that $\mathrm{mTOR}^{\mathrm{KO}} \mathrm{PMN}-\mathrm{MDSC}$ transfusion could promote a better recovery of donor-derived PMN-MDSCs.

Then, we measured donor-derived PMN-MDSCs and M-MDSCs in BM and SP on days 14 and 21 after transplantation. The percentage and absolute number of PMN-MDSCs remarkably increased in BM and SP of the $\mathrm{mTOR}^{\mathrm{KO}}$ PMN-MDSC-infused group (Figure $5 \mathrm{C}$ ). The immunosuppressive ability of PMN-MDSCs from the $\mathrm{mTOR}^{\mathrm{KO}}$ PMN-MDSC infusion group was also much more robust on day 21 compared to other groups (Figure 5D). Meanwhile, M-MDSCs possessed a powerful suppressive function but with no significant difference among groups (Supplementary Figure S6A). Overall, our results showed that although transfused $\mathrm{mTOR}^{\mathrm{KO}} \mathrm{PMN}-\mathrm{MDSC}$ could not maintain a long-lasting persistence in $\mathrm{BM}, \mathrm{SP}$, and $\mathrm{PB}$, they could promote the proliferation and functional recovery of donor-derived $\mathrm{PMN}$ MDSCs.

\section{DISCUSSION}

The sensor mTOR is important for various environmental or cellular changes, such as nutrient deprivation, energy insufficiency, and cytokine stimulation. Also, mTOR is important to control the fate of diverse immune cells (Powell et al., 2012; Yang et al., 2014). Generally, cytokines such as G-CSF, GM-CSF, IL-1 $\beta$, IL-6, IL-4, and S100A8/A9 are essential to induce immunosuppressive function of $\mathrm{BM}$-derived $\mathrm{PMN}$ MDSCs (Talmadge and Gabrilovich 2013). In the current study, we found that isolated $\mathrm{mTOR}^{\mathrm{KO}}$ PMN-MDSCs could directly exhibit a strong suppressive ability without long-term and complex cytokine induction in vitro. Consistent with previous studies, our results showed that mTOR inhibition could decrease M-MDSCs' immunosuppressive ability (Wu et al., 2016), which revealed that the mTOR signaling might have an opposite regulatory function on these two subpopulations. Thus, we investigated how mTOR regulates PMN-MDSCs' generation and function. According to Evrard et al. (2018), neutrophils in the BM can be identified by mass cytometry and cell cycle-based analyses as neutrophil precursors, immature neutrophils, and mature neutrophils. Among them, immature neutrophils have suppressive ability. Correspondingly, we found that the proportion of the immature subset increased in the $\mathrm{BM}$ of $\mathrm{mTOR}^{\mathrm{KO}}$ mice (Supplementary Figure S7). These findings implied that the mTOR deficiency maintained myeloid cells in an immature state, which might be consistent with its functional properties.

The JAK-STAT signaling is considered to play a critical role in the expansion and function of MDSCs (Vasquez-Dunddel et al., 2013; Waldmann and Chen 2017). STAT3 is an essential transcription factor that activates genes involved in the differentiation and proliferation of MDSCs, such as c-myc, 
cyclin D1, and S100A8/A9, and induces genes associated with suppressive functions including NADPH oxidase subunits, $\mathrm{p} 47^{\text {phox }}$ and $\mathrm{gp} 91^{\text {phox }}$, and C/EBP $\beta$ (Marigo et al., 2010). $\mathrm{C} / \mathrm{EBP} \beta$ is an intronless gene that generates three isoforms-liver activating protein ${ }^{\star}\left(\mathrm{LAP}^{\star}, 38 \mathrm{kDa}\right)$, liver activating protein (LAP, $35 \mathrm{kDa}$ ), and liver inhibitory protein (LIP, $20 \mathrm{kDa}$ ) - which are highly expressed in innate immune cells (Guo, Li, and Tang 2015). When mTORC1 activity is low (e.g., with the presence of rapamycin), the downstream translation of C/EBP $\beta$-LAP is favored (Bitto et al., 2021). We observed an increased level of C/EBP $\beta$-LAP in $\mathrm{mTOR}^{\mathrm{KO}} \mathrm{PMN}-$ MDSCs, which was STAT3 signal-dependent. The suppressive function of $\mathrm{mTOR}^{\mathrm{KO}} \mathrm{PMN}-\mathrm{MDSC}$ could be abolished when STAT3 activation or C/EBP $\beta$-LAP expression was obstructed. Therefore, we concluded that $\mathrm{mTOR}$ regulated the suppressive function of PMN-MDSCs via STAT3-C/EBP $\beta$ pathway activation. Recent studies have demonstrated that mTOR and STAT pathways interact to control and optimize both innate and adaptive immunity regulations. T cell-specific TSC1-deficient and RICTOR-deficient mice presented increased Tregs number, which was correlated with higher STAT5 activation and proliferation rates (Chen et al., 2013; Park et al., 2013). DCs treated with Torin 1, a catalytic mTOR inhibitor, were found to express lower SOCS3 levels, resulting in increased STAT3 activation, increased B7-H1 expression, and enhanced Tregs induction (Rosborough et al., 2013). In our study, we uncovered that STAT3 was up-regulated in $\mathrm{mTOR}^{\mathrm{KO}} \mathrm{PMN}-$ MDSCs, while its negative regulator Pias was significantly decreased. However, the relationship between mTOR and Pias needs to be further studied. We will carry out further experiments to identify whether STAT3 activation is a direct result of mTOR deficiency or a subsequent signaling cascade.

Adoptive transfusion of MDSCs has been reported to be an effective strategy to control aGVHD after allo-HSCT. In vitrogenerated MDSCs abrogated allogeneic antigen-specific $\mathrm{T}$ cell functions by skewing $\mathrm{T}$ cells into Th2, thereby preventing GVHD without affecting the GVL effect (Messmann et al., 2015). In our current study, we found that co-transplanting $\mathrm{mTOR}^{\mathrm{KO}}$ PMN-MDSCs with grafts could alleviate aGVHD while retaining the GVL effect. In previous studies, adoptive transferred MDSCs were mainly generated in vitro by cytokines or isolated from tumor-bearing mice. As BM PMN-MDSCs freshly obtained from WT mice presented limited suppressive function, M-MDSCs with natural powerful suppressive function were considered to be a better source of therapeutic cells (Lin et al., 2018). However, M-MDSCs are present only in a small fraction in the BM. leading to an insufficient amount for treatment. In contrast, PMN-MDSCs possessing a larger proportion and quantity and can be a better choice for cellular immunotherapy. Thus, we assumed that prophylactic infusion of $\mathrm{mTOR}^{\mathrm{KO}} \mathrm{PMN}-\mathrm{MDSC}$ could significantly reduce mortality and alleviate aGVHD. But, it was found before that the intense inflammatory environment could directly undermine the suppressive capacity of MDSCs, which was associated with their conversion toward a mature state (Koehn et al., 2015). Transfusing on day 14 after aGVHD occurrence led to an effect that is less than satisfactory, suggesting that the therapeutic ability of these cells was limited.

In the $\mathrm{mTOR}^{\mathrm{KO}} \mathrm{PMN}-\mathrm{MDSC}$ infusion group, the Th1/Th2 ratio was much lower and peripheral proinflammatory cytokines were maintained at a low level in serum, but the Tregs percentage was higher. Combined with the evidence that $\mathrm{mTOR}^{\mathrm{KO}} \mathrm{PMN}$ MDSCs could only play a preventive role but not a therapeutic effect, we speculated that the adoptive transferred $\mathrm{mTOR}^{\mathrm{KO}}$ PMN-MDSCs had a suppressive function at the very beginning of aGVHD and further stopped the cytokine storm amplification. Using CD45.1 and CD45.2 to distinguish adoptive transferred and donor-derived PMN-MDSCs, we found that the co-transplanted PMN-MDSCs could only persist for a short time in the $\mathrm{BM}$ and $\mathrm{PB}$. Previous studies found that the adoptive transfused MDSCs could be detected in the lymphoid organs and liver until day 30 after transplantation (Messmann et al., 2015). We assumed that co-transplanted MDSCs might rapidly migrate to the peripheral organs or differentiate to a mature state after transfusion. On aGVHD at a later stage, we detected a better quantitative and functional recovery of donor-derived PMNMDSCs in the $\mathrm{mTOR}^{\mathrm{KO}} \mathrm{PMN}-\mathrm{MDSC}$ transfusion group. $\mathrm{mTOR}^{\mathrm{KO}}$ PMN-MDSC transfusion plays an effective role in aGVHD prevention in a mouse model. However, the application of gene-edited MDSCs in clinical practice needs to be further explored due to the uncertain safety and technical constraints. The mTOR inhibitor rapamycin would become a potential alternative choice to regulate the differentiation and suppressive function of PMN-MDSCs. Our findings provide more evidence for the application of rapamycin for aGVHD control.

Overall, we demonstrated that mTOR is an effective intrinsic regulatory factor for PMN-MDSCs' differentiation and immunosuppressive function. Also, $\mathrm{mTOR}^{\mathrm{KO}} \mathrm{PMN}$ MDSC transfusion can be a therapeutic option to prevent cytokine storms at early stages and promote a quantitative and functional recovery of donor-derived PMN-MDSCs in aGVHD. Our findings indicate that mTOR manipulation of PMN-MDSCs might be an effective way in aGVHD prevention.

\section{DATA AVAILABILITY STATEMENT}

The original contributions presented in the study are publicly available. This data can be found here: BioProject: PRJNA726285.

\section{ETHICS STATEMENT}

The studies involving human participants were reviewed and approved by the Committee of the First Affiliated Hospital, School of Medicine, Zhejiang University. The patients/ participants provided their written informed consent to participate in this study. The animal study was reviewed and approved by the Institutional Animal Care and used Committee of Zhejiang University. 


\section{AUTHOR CONTRIBUTIONS}

$\mathrm{XL}$ and YL designed the study and conducted most of the experiments. QY and YL conducted some of the experiments, analyzed the data, and created some the figures. CW, SF, and LX conducted some of the experiments. YL and JS provided the research guidance. XL and YL prepared the first draft. YL, PQ, and $\mathrm{HH}$ provided subsequent revisions and revised the article. All authors contributed to the article and approved the submitted version.

\section{FUNDING}

This work was supported by grants from the National Natural Science Foundation of China (82000194, 82070179, and 81970158), the Key R and D projects of Science Technology

\section{REFERENCES}

Beauchamp, E. M., and Platanias, L. C. (2013). The Evolution of the TOR Pathway and its Role in Cancer. Oncogene 32 (34), 3923-3932. doi:10.1038/onc.2012.567 Bitto, A., Tatom, N., Krivak, T., Grotz, P., and Kaeberlein, M. (2021). Evidence that C/EBP- $\beta$ LAP Increases Fat Metabolism and Protects against Diet-Induced Obesity in Response to mTOR Inhibition. Front. Aging 2, 738512. doi:10.3389/ fragi.2021.738512

Bronte, V., Brandau, S., Chen, S. H., Colombo, M. P., Frey, A. B., Greten, T. F., et al. (2016). Recommendations for Myeloid-Derived Suppressor Cell Nomenclature and Characterization Standards. Nat. Commun. 7, 12150. doi:10.1038/ ncomms 12150

Chen, H., Zhang, L., Zhang, H., Xiao, Y., Shao, L., Li, H., et al. (2013). Disruption of TSC1/2 Signaling Complex Reveals a Checkpoint Governing Thymic CD4 + CD25 + Foxp3 + Regulatory T-cell Development in Mice. FASEB j. 27 (10), 3979-3990. doi:10.1096/fj.13-235408

D’Aveni, M., Rossignol, J., Coman, T., Sivakumaran, S., Henderson, S., Manzo, T., et al. (2015). G-CSF Mobilizes CD34+ Regulatory Monocytes that Inhibit GraftVersus-Host Disease. Sci. Transl Med. 7 (281), 281ra42. doi:10.1126/ scitranslmed.3010435

Delgoffe, G. M., Kole, T. P., Zheng, Y., Zarek, P. E., Matthews, K. L., Xiao, B., et al. (2009). The mTOR Kinase Differentially Regulates Effector and Regulatory $\mathrm{T}$ Cell Lineage Commitment. Immunity 30 (6), 832-844. doi:10.1016/ j.immuni.2009.04.014

Deng, Y., Yang, J., Luo, F., Qian, J., Liu, R., Zhang, D., et al. (2018). mTORMediated Glycolysis Contributes to the Enhanced Suppressive Function of Murine Tumor-Infiltrating Monocytic Myeloid-Derived Suppressor Cells. Cancer Immunol. Immunother. 67 (9), 1355-1364. doi:10.1007/s00262-0182177-1

Dugast, A.-S., Haudebourg, T., Coulon, F., Heslan, M., Haspot, F., Poirier, N., et al. (2008). Myeloid-derived Suppressor Cells Accumulate in Kidney Allograft Tolerance and Specifically Suppress Effector T Cell Expansion. J. Immunol. 180 (12), 7898-7906. doi:10.4049/jimmunol.180.12.7898

Edinger, M., Hoffmann, P., Ermann, J., Drago, K., Fathman, C. G., Strober, S., et al. (2003). CD4+CD25+ Regulatory T Cells Preserve Graft-Versus-Tumor Activity while Inhibiting Graft-Versus-Host Disease after Bone Marrow Transplantation. Nat. Med. 9 (9), 1144-1150. doi:10.1038/nm915

Evrard, M., Kwok, I. W. H., Chong, S. Z., Teng, K. W. W., Becht, E., Chen, J., et al. (2018). Developmental Analysis of Bone Marrow Neutrophils Reveals Populations Specialized in Expansion, Trafficking, and Effector Functions. Immunity 48 (2), 364-379.e8. doi:10.1016/j.immuni.2018.02.002

Fan, Q., Liu, H., Liang, X., Yang, T., Fan, Z., Huang, F., et al. (2017). Superior GVHD-free, Relapse-free Survival for G-BM to G-PBSC Grafts Is Associated with Higher MDSCs Content in Allografting for Patients with Acute Leukemia. J. Hematol. Oncol. 10, 135. doi:10.1186/s13045-017-0503-2
Department of Zhejiang Province (2020C03G2013586), and the Zhejiang Provincial Natural Science Foundation (LQ19H080006 and LY19H080008).

\section{ACKNOWLEDGMENTS}

We thank the support and help from the members of core facilities of the Zhejiang University School of Medicine and Laboratory Animal Center of Zhejiang University.

\section{SUPPLEMENTARY MATERIAL}

The Supplementary Material for this article can be found online at: https://www.frontiersin.org/articles/10.3389/fcell.2021.741911/ full\#supplementary-material

Gabrilovich, D. I., and Nagaraj, S. (2009). Myeloid-derived Suppressor Cells as Regulators of the Immune System. Nat. Rev. Immunol. 9 (3), 162-174. doi:10.1038/nri2506

Garcia, M. R., Ledgerwood, L., Yang, Y., Xu, J., Lal, G., Burrell, B., et al. (2010). Monocytic Suppressive Cells Mediate Cardiovascular Transplantation Tolerance in Mice. J. Clin. Invest. 120 (7), 2486-2496. doi:10.1172/Jci41628

Gomez, A., Espejo, C., Eixarch, H., Casacuberta-Serra, S., Mansilla, M. J., Sanchez, R., et al. (2014). Myeloid-Derived Suppressor Cells Are Generated during Retroviral Transduction of Murine Bone Marrow. Cel Transpl. 23 (1), 73-85. doi:10.3727/096368912x658971

Guan, Q., Blankstein, A. R., Anjos, K., Synova, O., Tulloch, M., Giftakis, A., et al. (2015). Functional Myeloid-Derived Suppressor Cell Subsets Recover Rapidly after Allogeneic Hematopoietic Stem/Progenitor Cell Transplantation. Biol. Blood Marrow Transplant. 21 (7), 1205-1214. doi:10.1016/j.bbmt.2015.04.015

Guo, L., Li, X., and Tang, Q.-Q. (2015). Transcriptional Regulation of Adipocyte Differentiation: A Central Role for CCAAT/Enhancer-binding Protein (C/EBP) ß. J. Biol. Chem. 290 (2), 755-761. doi:10.1074/jbc.R114.619957

Hess, A. D. (2006). Modulation of Graft-Versus-Host Disease: Role of Regulatory T Lymphocytes. Biol. Blood Marrow Transplant. 12 (1 Suppl. 2), 13-21. doi:10.1016/j.bbmt.2005.11.002

Highfill, S. L., Rodriguez, P. C., Zhou, Q., Goetz, C. A., Koehn, B. H., Veenstra, R., et al. (2010). Bone Marrow Myeloid-Derived Suppressor Cells (MDSCs) Inhibit Graft-Versus-Host Disease (GVHD) via an Arginase-1-dependent Mechanism that Is Up-Regulated by Interleukin-13. Blood 116 (25), 5738-5747. doi:10.1182/blood-2010-06-287839

Hill, G. R., Crawford, J. M., Cooke, K. R., Brinson, Y. S., Pan, L., and Ferrara, J. L. M. (1997). Total Body Irradiation and Acute Graft-Versus-Host Disease: the Role of Gastrointestinal Damage and Inflammatory Cytokines. Blood 90 (8), 3204-3213. doi:10.1182/blood.v90.8.3204

Koehn, B. H., Apostolova, P., Haverkamp, J. M., Miller, J. S., McCullar, V., Tolar, J., et al. (2015). GVHD-associated, Inflammasome-Mediated Loss of Function in Adoptively Transferred Myeloid-Derived Suppressor Cells. Blood 126 (13), 1621-1628. doi:10.1182/blood-2015-03-634691

Koreth, J., Matsuoka, K.-i., Kim, H. T., McDonough, S. M., Bindra, B., Alyea, E. P., 3rd, et al. (2011). Interleukin-2 and Regulatory T Cells in Graft-Versus-Host Disease. N. Engl. J. Med. 365 (22), 2055-2066. doi:10.1056/NEJMoa1108188

Korngold, R., and Sprent, J. (1987). Variable Capacity of L3T4+ T Cells to Cause Lethal Graft-Versus-Host Disease across Minor Histocompatibility Barriers in Mice. J. Exp. Med. 165 (6), 1552-1564. doi:10.1084/jem.165.6.1552

Le Blanc, K., Frassoni, F., Ball, L., Locatelli, F., Roelofs, H., Lewis, I., et al. (2008). Blood Developmental Committee of the European Group for, and Transplantation Marrow Mesenchymal Stem Cells for Treatment of SteroidResistant, Severe, Acute Graft-Versus-Host Disease: a Phase II Study. The Lancet 371 (9624), 1579-1586. doi:10.1016/S0140-6736(08)60690-X

Lin, Y., Wang, B., Shan, W., Tan, Y., Feng, J., Xu, L., et al. (2018). mTOR Inhibitor Rapamycin Induce Polymorphonuclear Myeloid-Derived Suppressor Cells 
Mobilization and Function in Protecting against Acute Graft-Versus-Host Disease after Bone Marrow Transplantation. Clin. Immunol. 187, 122-131. doi:10.1016/j.clim.2017.11.005

Ling, X., and Arlinghaus, R. B. (2005). Knockdown of STAT3 Expression by RNA Interference Inhibits the Induction of Breast Tumors in Immunocompetent Mice. Cancer Res. 65 (11), 2532-2536. doi:10.1158/0008-5472.CAN-04-2425

Lv, M., Zhao, X.-S., Hu, Y., Chang, Y.-J., Zhao, X.-Y., Kong, Y., et al. (2015). Monocytic and Promyelocytic Myeloid-Derived Suppressor Cells May Contribute to G-CSF-Induced Immune Tolerance in Haplo-Identical Allogeneic Hematopoietic Stem Cell Transplantation. Am. J. Hematol. 90 (1), E9-E16. doi:10.1002/ajh.23865

MacDonald, K. P. A., Rowe, V., Clouston, A. D., Welply, J. K., Kuns, R. D., Ferrara, J. L. M., et al. (2005). Cytokine Expanded Myeloid Precursors Function as Regulatory Antigen-Presenting Cells and Promote Tolerance through IL-10producing Regulatory T Cells. J. Immunol. 174 (4), 1841-1850. doi:10.4049/ jimmunol.174.4.1841

Marigo, I., Bosio, E., Solito, S., Mesa, C., Fernandez, A., Dolcetti, L., et al. (2010). Tumor-Induced Tolerance and Immune Suppression Depend on the C/EBP $\beta$ Transcription Factor. Immunity 32 (6), 790-802. doi:10.1016/ j.immuni.2010.05.010

Messmann, J. J., Reisser, T., Leithäuser, F., Lutz, M. B., Debatin, K.-M., and Strauss, G. (2015). In Vitro-generated MDSCs Prevent Murine GVHD by Inducing Type 2 T Cells without Disabling Antitumor Cytotoxicity. Blood 126 (9), 1138-1148. doi:10.1182/blood-2015-01-624163

Mougiakakos, D., Jitschin, R., von Bahr, L., Poschke, I., Gary, R., Sundberg, B., et al. (2013). Immunosuppressive CD14+HLA-DRlow/neg Ido+ Myeloid Cells in Patients Following Allogeneic Hematopoietic Stem Cell Transplantation. Leukemia 27 (2), 377-388. doi:10.1038/leu.2012.215

Nakamura, T., Nakao, T., Yoshimura, N., and Ashihara, E. (2015). Rapamycin Prolongs Cardiac Allograft Survival in a Mouse Model by Inducing MyeloidDerived Suppressor Cells. Am. J. Transplant. 15 (9), 2364-2377. doi:10.1111/ ajt.13276

Park, Y., Jin, H.-S., Lopez, J., Elly, C., Kim, G., Murai, M., et al. (2013). TSC1 Regulates the Balance between Effector and Regulatory T Cells. J. Clin. Invest. 123 (12), 5165-5178. doi:10.1172/Jci69751

Perobelli, S. M., Mercadante, A. C. T., Galvani, R. G., Gonçalves-Silva, T., Alves, A. P. G., Pereira-Neves, A., et al. (2016). G-CSF-Induced Suppressor IL$10+$ Neutrophils Promote Regulatory T Cells that Inhibit Graft-Versus-Host Disease in a Long-Lasting and Specific Way. J Immunol. 197 (9), 3725-3734. doi:10.4049/jimmunol.1502023

Powell, J. D., Pollizzi, K. N., Heikamp, E. B., and Horton, M. R. (2012). Regulation of Immune Responses by mTOR. Annu. Rev. Immunol. 30, 39-68. doi:10.1146/ annurev-immunol-020711-075024

Rao, R. R., Li, Q., Odunsi, K., and Shrikant, P. A. (2010). The mTOR Kinase Determines Effector versus Memory CD8 + T Cell Fate by Regulating the Expression of Transcription Factors T-Bet and Eomesodermin. Immunity 32 (1), 67-78. doi:10.1016/j.immuni.2009.10.010

Rieber, N., Wecker, I., Neri, D., Fuchs, K., Schäfer, I., Brand, A., et al. (2014). Extracorporeal Photopheresis Increases Neutrophilic Myeloid-Derived Suppressor Cells in Patients with GvHD. Bone Marrow Transpl. 49 (4), 545-552. doi:10.1038/bmt.2013.236

Ringdén, O., Uzunel, M., Rasmusson, I., Remberger, M., Sundberg, B., Lönnies, H., et al. (2006). Mesenchymal Stem Cells for Treatment of Therapy-Resistant Graft-Versus-Host Disease. Transplantation 81 (10), 1390-1397. doi:10.1097/ 01.tp.0000214462.63943.14

Rosborough, B. R., Raïch-Regué, D., Matta, B. M., Lee, K., Gan, B., DePinho, R. A., et al. (2013). Murine Dendritic Cell Rapamycin-Resistant and Rictor-independent mTOR Controls IL-10, B7-H1, and Regulatory T-Cell Induction. Blood 121 (18), 3619-3630. doi:10.1182/blood-2012$08-448290$

Talmadge, J. E., and Gabrilovich, D. I. (2013). History of Myeloid-Derived Suppressor Cells. Nat. Rev. Cancer 13 (10), 739-752. doi:10.1038/nrc3581

Thomson, A. W., Turnquist, H. R., and Raimondi, G. (2009). Immunoregulatory Functions of mTOR Inhibition. Nat. Rev. Immunol. 9 (5), 324-337. doi:10.1038/nri2546
Vasquez-Dunddel, D., Pan, F., Zeng, Q., Gorbounov, M., Albesiano, E., Fu, J., et al. (2013). STAT3 Regulates Arginase-I in Myeloid-Derived Suppressor Cells from Cancer Patients. J. Clin. Invest. 123 (4), 1580-1589. doi:10.1172/Jci60083

Vendramin, A., Gimondi, S., Bermema, A., Longoni, P., Rizzitano, S., Corradini, P., et al. (2014). Graft Monocytic Myeloid-Derived Suppressor Cell Content Predicts the Risk of Acute Graft-Versus-Host Disease after Allogeneic Transplantation of Granulocyte Colony-Stimulating Factor-Mobilized Peripheral Blood Stem Cells. Biol. Blood Marrow Transplant. 20 (12), 2049-2055. doi:10.1016/j.bbmt.2014.09.011

Vogelsang, G. B., Lee, L., and Bensen-Kennedy, D. M. (2003). Pathogenesis and Treatment of Graft-Versus-Host Disease after Bone Marrow Transplant. Annu. Rev. Med. 54, 29-52. doi:10.1146/annurev.med.54.101601.152339

Waldmann, T. A., and Chen, J. (2017). Disorders of the JAK/STAT Pathway in T Cell Lymphoma Pathogenesis: Implications for Immunotherapy. Annu. Rev. Immunol. 35, 533-550. doi:10.1146/annurev-immunol-110416-120628

Wang, K., Lv, M., Chang, Y.-J., Zhao, X.-Y., Zhao, X.-S., Zhang, Y.-Y., et al. (2019). Early Myeloid-Derived Suppressor Cells (HLA-DR-/lowCD33+CD16-) Expanded by Granulocyte colony-stimulating Factor Prevent Acute GraftVersus-Host Disease (GVHD) in Humanized Mouse and Might Contribute to Lower GVHD in Patients post Allo-HSCT. J. Hematol. Oncol. 12 (1), 31. doi:10.1186/s13045-019-0710-0

Wei, C., Wang, Y. X., Ma, L., Wang, X., Chi, H., Zhang, S., et al. (2018). Rapamycin Nano-Micelle Ophthalmic Solution Reduces Corneal Allograft Rejection by Potentiating Myeloid-Derived Suppressor Cells' Function. Front. Immunol. 9, 2283. doi:10.3389/fimmu.2018.02283

Wu, T., Zhao, Y., Wang, H., Li, Y., Shao, L., Wang, R., et al. (2016). mTOR Masters Monocytic Myeloid-Derived Suppressor Cells in Mice with Allografts or Tumors. Sci. Rep. 6, 20250. doi:10.1038/srep20250

Yang, H., Wang, X., Zhang, Y., Liu, H., Liao, J., Shao, K., et al. (2013). Modulation of TSC-mTOR Signaling on Immune Cells in Immunity and Autoimmunity. J. Cel. Physiol. 229 (1), 17-26. doi:10.1002/jcp.24426

Zhang, J., Chen, H.-M., Ma, G., Zhou, Z., Raulet, D., Rivera, A. L., et al. (2019). The Mechanistic Study behind Suppression of GVHD while Retaining GVL Activities by Myeloid-Derived Suppressor Cells. Leukemia 33 (8), 2078-2089. doi:10.1038/s41375-019-0394-z

Zhang, Y., Bi, Y., Yang, H., Chen, X., Liu, H., Lu, Y., et al. (2014). mTOR Limits the Recruitment of CD11b+ Gr1+ Ly6Chigh Myeloid-Derived Suppressor Cells in Protecting against Murine Immunological Hepatic Injury. J. Leukoc. Biol. 95 (6), 961-970. doi:10.1189/jlb.0913473

Zhao, D., Zhang, C., Yi, T., Lin, C.-L., Todorov, I., Kandeel, F., et al. (2008). In Vivo-activated CD103+CD4+ Regulatory T Cells Ameliorate Ongoing Chronic Graft-Versus-Host Disease. Blood 112 (5), 2129-2138. doi:10.1182/blood-200802-140277

Zhou, Z., French, D. L., Ma, G., Eisenstein, S., Chen, Y., Divino, C. M., et al. (2010). Development and Function of Myeloid-Derived Suppressor Cells Generated from Mouse Embryonic and Hematopoietic Stem Cells. Stem Cells 28 (3), 620-632. doi:10.1002/stem.301

Conflict of Interest: The authors declare that the research was conducted in the absence of any commercial or financial relationships that could be construed as a potential conflict of interest.

Publisher's Note: All claims expressed in this article are solely those of the authors and do not necessarily represent those of their affiliated organizations, or those of the publisher, the editors, and the reviewers. Any product that may be evaluated in this article, or claim that may be made by its manufacturer, is not guaranteed or endorsed by the publisher.

Copyright $\odot 2021 \mathrm{Li}, \mathrm{Li}, \mathrm{Yu}, \mathrm{Xu}, \mathrm{Fu}$, Wei, Wang, Luo, Shi, Qian, Huang and Lin. This is an open-access article distributed under the terms of the Creative Commons Attribution License (CC BY). The use, distribution or reproduction in other forums is permitted, provided the original author(s) and the copyright owner(s) are credited and that the original publication in this journal is cited, in accordance with accepted academic practice. No use, distribution or reproduction is permitted which does not comply with these terms. 